\title{
Trajectory of Innovation in Emerging Industries: Evidence from the Global Wind Power Industry
}

Snehal Suyash Awate

Ph.D. awarded by Temple University, USA, December 2013

NeW INDUStRIES APPEAR WHEN KNOWLEDGE from multiple industries is recombined to create revolutionary products or services. While this industry-creating role of knowledge recombinations is profound, their geographic sources are attributed to few knowledge hotspots often located in advanced economies. This dissertation reevaluates the geographic clustering of innovation in new industries. Contrary to the established view, we find that these industries experience a wider geographic circumference of innovation that spans even the emerging economies. The increasing appearance of new locations in the global innovation systems of these industries indicates lower barriers to entry and weaker first mover advantages for locations.

These contrasting results become more pronounced when viewed in the light of the established wisdom on new industries. Newly emerging industries are characterized by uncertainty in terms of strategy, operations, external environment and demand. Technological regime experiences frequent changes. Thus, what appears to be a converging dominant design and steady output growth may be disrupted by discontinuities (Klepper, 1997). The competition is based on technological expertise to manage as well as shape the evolving technological regime. In such a context, geographic proximity among the innovative locations, in other words, agglomeration benefits, are shown to improve spillovers of knowledge which is often highly tacit in the emerging industry phases (Audretsch \& Feldman, 1996a, 1996b). Tuning into the local buzz (Bathelt et al., 2004) of such clusters may help to foresee the technological trajectory, reduce uncertainty and generate early-stage innovations. The established view on new industries thus leaves little room for entry of new locations into the innovation system of these industries and implies major first mover advantage for existing locations. Further, the technologically-intensive nature of the competition precludes existence of young, knowledge-disadvantaged locations from emerging economies.

We support our contrasting findings by building on two characteristic features of today's knowledge economy, namely the global dispersion of technology (Cantwell \& Mudambi, 2005) and the growing geographic spread of value creation (Mudambi, 2008). Multinational enterprises (MNEs) are indeed expanding their R\&D networks to tap into dispersed knowledge sources. Lower spatial costs have led to an increasing fine slicing of global value chain shifting the economic activity from trade-in-goods to trade-in-activities. We argue that the established view on the geography of innovation in emerging industries was rooted in the trade-ingoods era. But the trade-in-activities feature of today's economy allows for easier entry into the global innovation system and wider innovation geography.

We use the global wind power industry as the study setting. The industry came into existence in the early 1980s after the oil crises of the late 1970s. Since then, the industry has witnessed establishment of dominant design, steady output growth, shakeouts, changing policy regimes and technological discontinuities - characteristics of emerging industries. We study innovation geography of the wind power industry by employing a novel analysis in which innovation is unpacked into its constituent dimensions, namely technological, geographic, and the people dimension occupied by inventors. The three-dimensional analysis is conducted on the entire population of wind turbine patents from the United States Patents and Trademarks Office database.
Figure1: Network Indicating Location Centrality

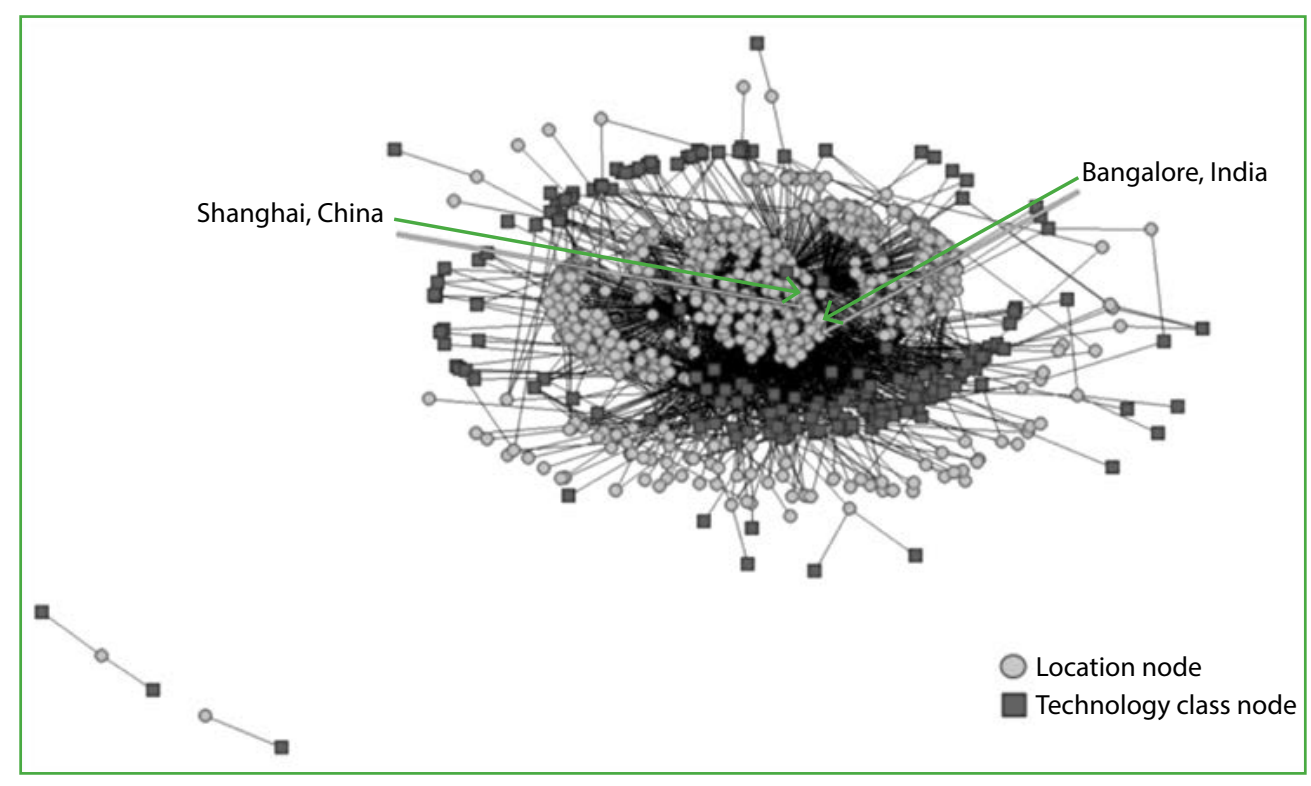




\section{Innovation Breadth, Innovation Depth and Geography}

All scientific advances occur through two distinct though correlated processes. These have been termed "integration" (connecting diverse bodies of knowledge) and "specialization" (deeper analysis of the study area) (Mudambi, Hannigan, \& Kline, 2012). The integration process can be measured by the diversity of the innovative process. In a like manner, the specialization process can be gauged in terms of the extent of specific and focused prior knowledge extant and used. In this sense, integration and specialization may be operationalized by the terms "breadth" and "depth" respectively. Breadth captures the number of discrete knowledge elements involved in creating innovations, that is, their technological scope. Locations that contain and support a wide variety of industries and technologies exhibit a high breadth of innovation. Depth, on the other hand, captures how well certain technologies are known. It develops as R\&D activities continue in certain technologies. The locations that contain and support a great concentration of certain technologies exhibit high depth in those technologies.

We measure innovation breadth as the number of active technologies at a location and innovation depth as the extent of innovative activities in the set of local technologies. By applying network analysis, we examine how innovation breadth and depth at a location impact its innovation performance measured by its centrality in the global innovation system (Figure 1). We find that both innovation breadth and depth have negative curvilinear effects on the location's innovation performance. However, breadth has a much larger impact than depth, suggesting that innovation performance is more sensitive to breadth than depth (Figure 2). We further argue that breadth can develop faster than depth, which implies that newer locations can undertake a breadth-focused strategy and accelerate their innovation performance. As seen in Figure 1, Shanghai, China, and Bangalore, India, serve as the examples of this result. Both these locations are late-entrants (2004 and 2006 respectively) in the wind industry's innovation system, yet they became much central by 2011 .

\section{Figure 2: Innovation Breadth versus Depth}

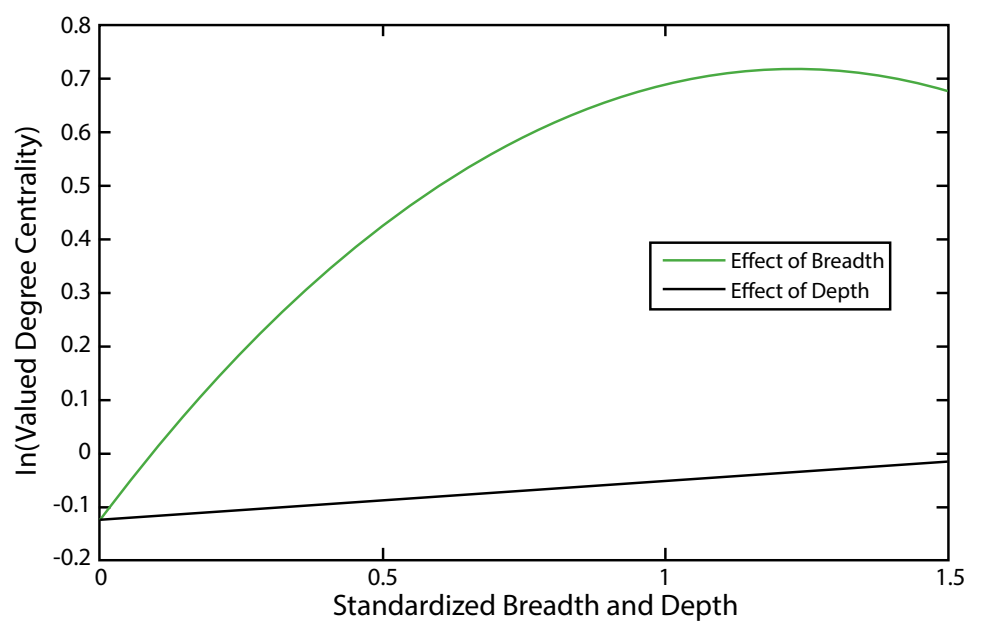

Figure 3 shows the innovation geography of the wind power industry by 2011. It is evident that the triad nations are most certainly the innovation leaders. However, the figure does highlight other non-triad locations such as those in China, India, Southeast Asia, Middle East and Australia. These newer locations do not yet have as heavy a concentration of innovative activity as in the triad nations; however, their very presence is indicative of the widening innovation geography of the emerging wind power industry.

\section{Role of Emerging Economies}

Figure 3 also highlights the growing presence of emerging economy locations in the industry's innovation system. We focus on these locations and study how firms located in emerging economies enter the innovation systems of emerging industries and catch-up with industry-leading firms. We define catch-up as the process of capability upgrading that the industry laggards undertake to get on par with the industry leaders. In that sense, catch-up of emerging economy firms is difficult as they work to overcome their late entry as well as their knowledge-disadvantaged background.

We find that catch-up is of two kinds, namely catch-up in (i) output capabilities and (ii) innovation capabilities. Output capabilities embrace knowledge about the overall technology of the product and can often be acquired in the market, especially in emerging industries. Innovation capabilities, however, necessitate more profound knowledge of the overall technology and require firms to know more than the technology of the final product. We find that output catch-up occurs much earlier than innovation catch-up. This finding has important implications when viewed in the context of emerging economy firms. As seen in a number of industries, emerging economy MNEs (EMNEs) are rapidly catching up with the industry frontier. We argue that this to a large extent can be explained by their focus on output catch-up. Therefore, while many EMNEs appear to have caught up with incumbent advanced economy MNEs, we suggest that this catch-up relates mostly to EMNEs' output capabilities and not their innovation capabilities. We find that their innovation catch-up is a slow process primarily undertaken by accessing state-of-the-art knowledge by acquiring foreign knowledge-bearing firms. Accessing knowledge requires closer interaction and negotiation with an R\&D subsidiary that may be more powerful and driven by motives other than that of the EMNE.

If innovation catch-up is slow for emerging economy firms, the obvious next question concerns the appearance of emerging economy locations in Figure 3. Locations embody the knowledge of both the local firms and foreign firms' subsidiaries. That results in a much broader and deeper knowledge base than any single firm leading to faster innovation catch-up of locations. Further, we find that the value chain fine slicing associated with today's trade-in-activities era also applies to $R \& D$ whereby the exploitative $R \& D$ is often fine sliced and its relatively standardized slices are moved to emerging economy locations. Among them, those locations that support a broad range of related technolo- 


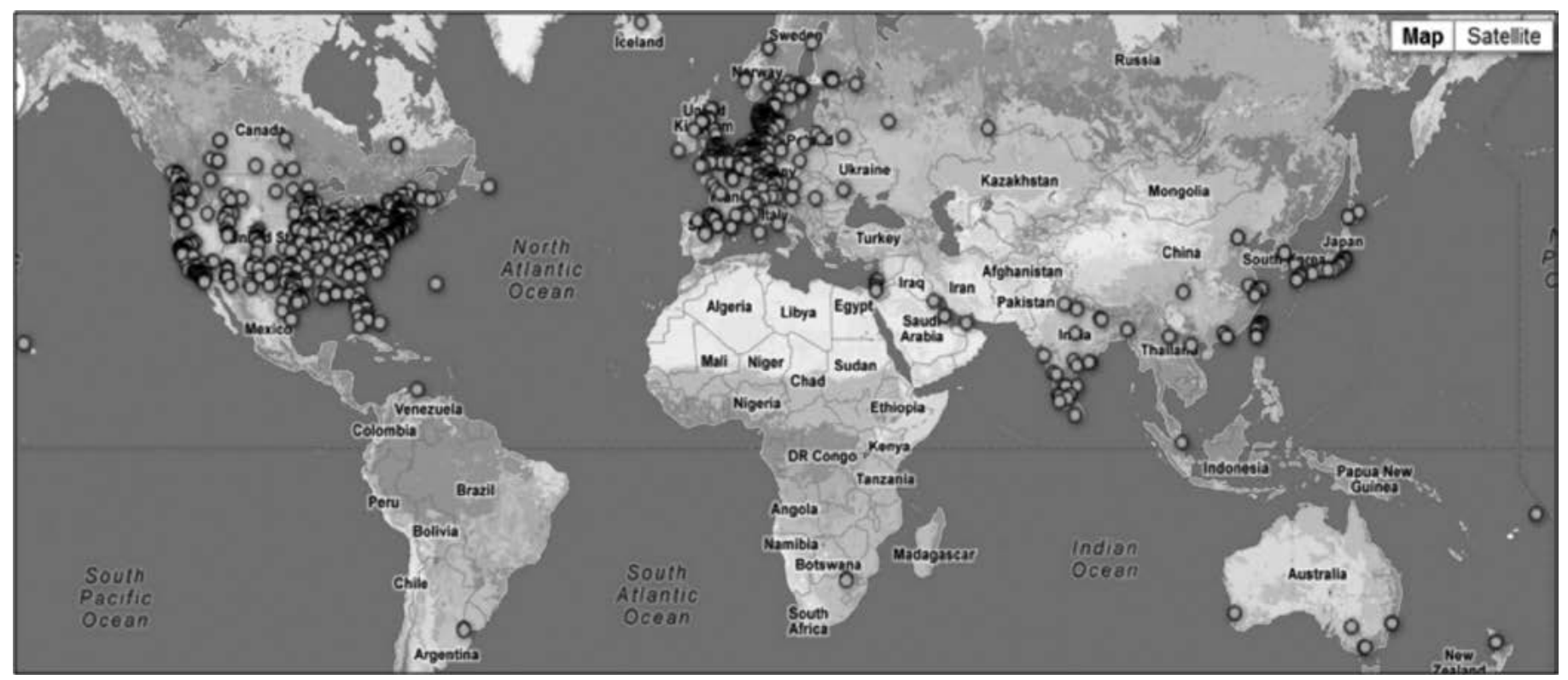

gies and thus high innovation breadth become successful innovators in the emerging wind power industry.

\section{References}

Audretsch, D., \& Feldman, M. 1996a. R\&D spillovers and the geography of innovation and production. American Economic Review, 86(3): 630-640.

Audretsch, D., \& Feldman M. 1996b. Industry clusters and the industry life cycle. Review of Industrial Organization, 11: 253-273.

Bathelt, H., Malmber,g A., \& Maskell P. 2004. Clusters and knowledge: Local buzz, global pipelines and the process of knowledge creation. Progress in Human Geography, 28(1): 31-56.

Cantwell, J., \&Mudambi, R. 2005. MNE competence-creating subsidiary mandates. Strategic Management Journal, 26(12): 1109-1128.

Klepper, S. 1997. Industry life cycles. Industrial and Corporate Change, 6(1): 145-181.

Mudambi, R. 2008. Location, control and innovation in knowledgeintensive industries. Journal of Economic Geography, 8(5): 699-725.

Mudambi, R., Hannigan, T., \& Kline, W. 2012. Advancing science on the knife's edge: integration and specialization in management PhD programs. Academy of Management Perspectives, 26(3): 83-105.
Snehal Awate is an Assistant Professor of Strategy at the Indian School of Business. Her research explores knowledge management strategies of emerging economy multinationals in newly emerging industries, particularly the renewable energy industries. She received her PhD from Temple University. Her work has appeared in the Journal of International Business Studies and the Global Strategy Journal, among others. 